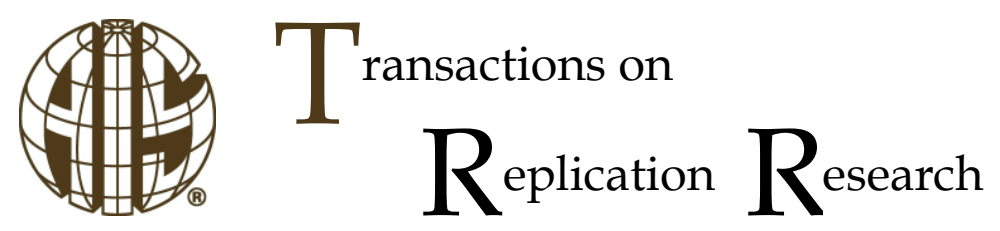

Conceptual Replication

\title{
Impact of ERP Implementation on Business Process Outcomes: A Replication of a United States Study in a Sub-Saharan African Nation
}

\author{
David Asamoah \\ Department of Information Systems and Decision Sciences, KNUST, Ghana \\ dasamoah.ksb@knust.edu.gh
}

\section{Francis Kofi Andoh-Baidoo}

Department of Computer Information Systems and Quantitative Methods, University of Texas Rio Grande Valley, USA

andohbaidoof@utpa.edu
Benjamin Agyei-Owusu

Department of Information Systems and Decision

Sciences, KNUST, Ghana

bagyeiowusu@gmail.com

Abstract:

This study is a conceptual replication of Karimi et al.'s (2007) study on the impact of ERP implementations on business process outcomes among US manufacturing firms in a Sub-Saharan African (SSA) nation. The results of the measurement model are valid and reliable, which are consistent and comparable with that of the original study, enhancing the external validity of the constructs proposed in the original model. However, only one of the four hypotheses tested in the structural model was confirmed in the current study although all four were supported in the original study. While the original model was tested on manufacturing firms in the US, the replicated study was carried out in several industries in Ghana, a SSA nation. Thus the differences in the structural model results do not invalidate the original model but suggest the need for capturing contextual or environmental variables such as culture, industry, ethical behavior, and data culture in order to enhance the external validity and theoretical contribution of the original model in the SSA context.

Keywords: ERP, Replication, Sub-Sahara Africa, Business Process Outcome

The manuscript was received 1/27/2015 and was with the authors 3 months for one revision. 


\section{Introduction}

ERP implementation usually results in enhanced business processes which often translates into improved business performance (Elbashir et al., 2008; Karimi et al., 2007), but not all organizations experience such benefits (Alshawi et al., 2004; Kim et al., 2005; Scot and Vessey, 2002; Soh and Sia, 2004; Voordijk et al., 2005). While the results of prior ERP benefits research are intriguing, most of the studies mainly focused on developed nations, particularly North America and Europe (Abdelghaffar and Abdel Azim, 2010; Huang et al., 2004; Huang and Palvia, 2001). One of the reasons for such a narrow focus is that about $88 \%$ of the ERP market is from North American and European countries (AMR, 2008; Scott and Shepherd, 2002). However, recent economic growth in many developing countries has led to a rise in ERP systems implementation in these economies (Avgerou, 2008; Huang and Palvia, 2001; Otieno, 2005).

This study is a conceptual replication (Dennis and Valacich, 2014) of the study of Karimi et al. (2007) which explored the impact of ERP implementation on business process outcomes using manufacturing firms in the US. We used data from firms that have implemented ERP systems in Ghana, a developing SSA country. Ghana is a rapidly developing country that achieved middle-income status in 2011 (Moss and Majerowicz, 2012). Since the mid-1980s, various governments have implemented many economic reforms and liberalization programs geared towards infrastructural and capacity building, economic growth, and improving the well-being of its citizens (Amoako-Gyampah and Acquaah, 2008). The country has also experienced significant growth in the banking and telecommunications sectors leading to the development of a vibrant ICT base in the country. Ghana placed third, and in the process became one of the only two African countries included in the list of potential future IT outsourcing locations, ahead of countries such as Korea, Malaysia, Mauritius, Nepal, Senegal, Sri Lanka, Taiwan, and Thailand (Davis et al., 2006). However challenges like corruption (Transparency International, 2012), poor data culture (Hung and Chang, 2005) and poor organizational control amongst SSA businesses (Mbarika et al., 2005; McDade and Spring, 2005) serve as major challenges to conducting business in the region.

The paper makes several contributions to practice and theory. First, the replication helps in strengthening theory on ERP benefits by examining the original research model in a different environment (Dennis and Valacich, 2014; Tsang and Kwan, 1999). Second, the replication suggests that the constructs of Karimi et al (2007) are relevant in the new environment but the model needs to be expanded to include contextual variables that are not captured in the original model. This is because extant literature suggests that business environment exerts influence on the successful adoption and use of IT (Chou and Chang, 2008; Gargeya and Brady, 2005; Ragowsky et al., 2000; Roztocki and Weistroffer, 2008, 2011; Soh and Sia, 2004; Zhang et al., 2002). Third, our study contributes to bridging the information systems research gap existing between developed and developing nations. Understanding the impact of ERP systems in developing nations should be of interest to both practitioners and academics as it presents a new and significantly different context to most existing studies (Roztocki and Weistroffer, 2009, 2011). Studies that explore the specific case of ERP implementation in SSA countries are thus necessary to expand our understanding and improve the success of ERP implementations in the sub-region.

The rest of the paper is organized as follows. The research model is presented in the next section, followed by the research method. We then present the results of the current study and compare them with Karimi et al.'s (2007). This is followed by discussion. Finally, we conclude the paper with implications and suggested potential future research.

\section{Research Model and hypotheses}

The theoretical model used in this research is adopted from the study of Karimi et al. (2007) on the impact of ERP implementation on business process outcomes among US manufacturing firms. Karimi et al. (2007) explored ERP implementation from a technological diffusion perspective. They assert that the extent of ERP implementation impacts positively on business process outcomes, and that the impact is enhanced by high ERP radicalness and an effective ERP delivery system. The results from the study of Karimi et al. (2007) are presented in Figure 1.

The four main constructs explored by Karimi et al. (2007) were adopted in this study, together with their sub-constructs. Appendix 1 presents a summary of all the constructs in the model and their acronyms, dimensions, and indicates whether they are formative or reflective constructs. The four hypotheses that 
guide this study are presented below. The theoretical discussions of the hypotheses are presented in more detail in Karimi et al. (2007).

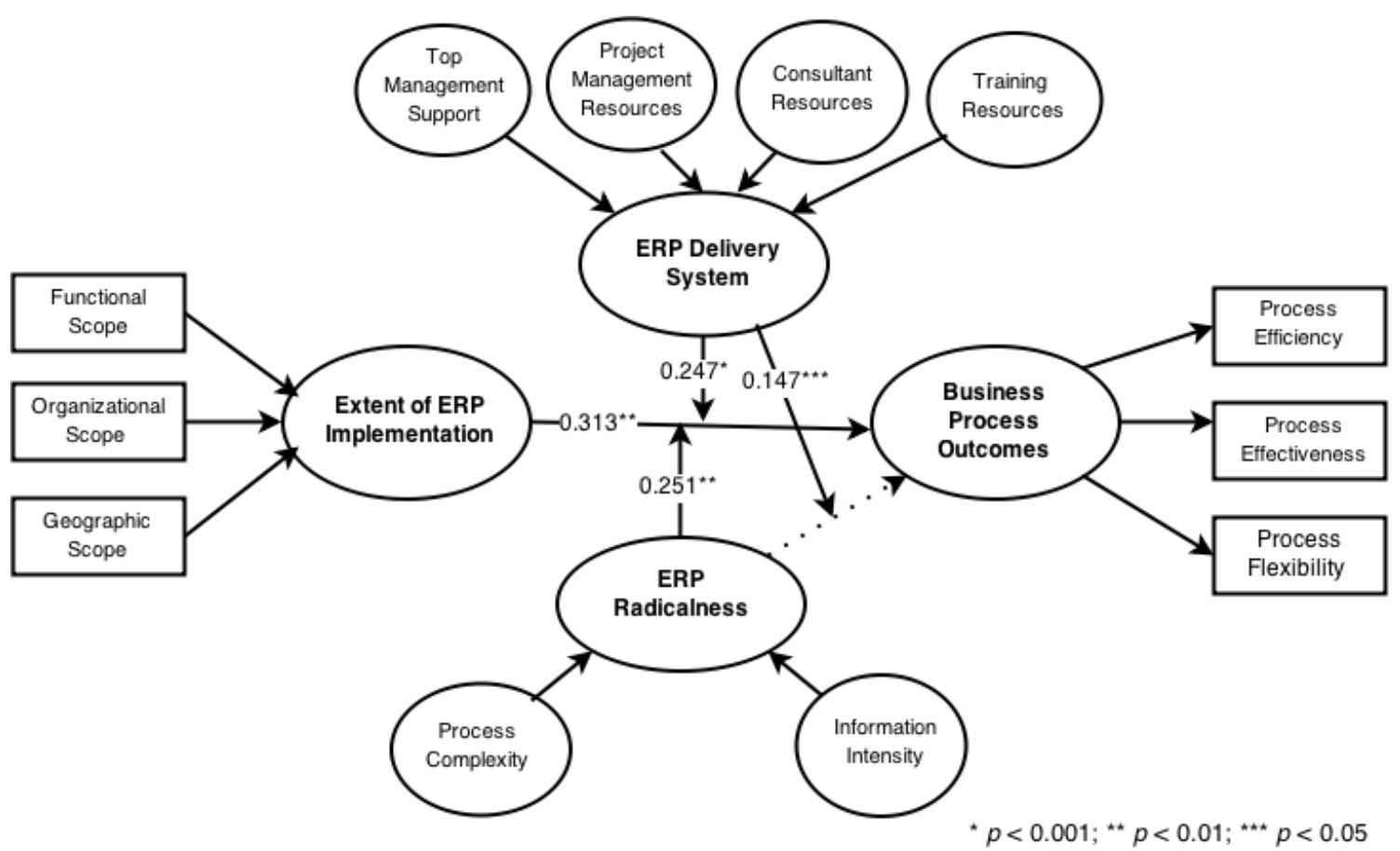

Figure 1. Research Model

Hypothesis 1: Extent of ERP implementation has a positive association with higher business process outcomes.

Hypothesis 2: Greater extent of ERP implementation in conjunction with greater delivery system support is positively associated with higher business process outcomes.

Hypothesis 3: Greater Extent of ERP implementation in conjunction with greater ERP radicalness is positively associated with higher business process outcomes.

Hypothesis 4: Greater ERP radicalness in conjunction with greater ERP delivery system support is positively associated with higher business process outcomes.

\section{Research Methodology}

Tsang and Kwan (1999) present two assumptions for replication studies: (1) research method employed in the replicated study is same as that in the original study, and (2) replicated study should not be done before the original study is completed. Our study satisfies both assumptions. Similarly, there is consistency in scales used in both studies satisfying additional requirement for replication studies (Kettinger and Lee, 1999).

Berthon et al. (2002) and Tsang and Kwan (1999) in classifying replication studies identify "pure" and "exact" replications respectively as ideal cases for replication, but acknowledge "extension and generalization" types of replication as the most occurring in the field of organization science and in information systems. Both agree that extension and generalization are most applied method because of difficulty in controlling parameters, and that at the minimum, the time parameter changes. Our research falls into the extension and generalization class of replication as presented in both Berthon et al. (2002) and Tsang and Kwan (1999) frameworks. Dennis and Valachich (2014) have also classified replication research into three categories: exact, methodological and conceptual. Our research fits into the 
conceptual category. Dennis and Valachich (2014, p. 3) noted that "conceptual replications are the strongest form of replication because they ensure that there is nothing idiosyncratic about the wording of items, the execution of treatments, or the culture of the original context that would limit the research conclusions". This assertion is in agreement with views of Tsang and Kwan (1999) and Berthon et al. (2002) that extensions and generalizations enhance external generalization of the original theoretical model.

In order to achieve the objectives of this work and to test the hypotheses presented, we conducted a survey of Ghanaian firms that had implemented ERP systems. While we used the same theory and the same research method as the original study, our sample was different in terms of country and industry. After extensive search in collaboration with ERP consultants, we identified a population of two hundred and fifty (250) firms that had implemented ERP systems in thirteen industries. Letters were sent to the CEOs of the 250 institutions requesting for the participation of their firms in the survey. 150 out of the 250 institutions wrote back to express interest in the survey. Questionnaires were issued to these 150 firms. The chief information officer or the highest IT personnel in these organizations was the targeted respondent to the questionnaire. After about three follow-ups of reminders through telephone calls, a total of 130 responses were retrieved, representing an initial response rate of $52 \%$ of identified firms. Questionnaires with greater than $10 \%$ of responses missing were discarded as recommended (Hair et al., 2010; Rubin, 1976). Ten respondent questionnaires were thus discarded due to missing data while additional 5 responses were unusable. Thus, the final number of usable responses was 115 , representing a $46 \%$ response rate.

The items used to measure the constructs presented in the research model were largely adopted from the study of Karimi et al. (2007). In order to ensure that all items fit the slightly different context of Ghanaian firms and industries other than manufacturing, minor modifications were made being careful to retain the original meanings of the research items.

\section{Data Analyses and Results}

\subsection{Demographic data}

Analysis of the demographic data collected revealed that $65.2 \%$ of the firms were solely Ghanaian owned, $28.7 \%$ foreign owned and $4.3 \%$ joint ventures. Majority $(86.1 \%)$ of the firms in the study were private organizations. The demographic data also revealed that $79.1 \%$ of firms reported having over 100 employees, falling under the large organizations category, based on the National Board for Small Scale and Industry's (NBSSI) classification for Ghanaian industries. Again, analysis by firm's revenue indicated that the vast majority (about $78.3 \%$ ) of the firms reported annual revenue of more than one million Ghana cedis (about US \$260,000), and thus are considered as large firms (Oppong et al., 2014). The composition of firms by industry revealed a good representation of the all thirteen industries identified in the population with "financial services" being the most predominant category. The full demographic data is presented in Table 1.

\subsection{Measurement Model Analysis}

The Partial Least Squares (PLS) method employed in the original study was used in the replication to test the hypothesized research model and hypotheses, although different software, SmartPLS version 2, was used. It is suggested that the use of PLS requires a sample size of at least ten times the number of paths that connect with the endogenous variable with the most paths originating at exogenous variables (Barclay et al., 1995; Chin, 1998). Since the endogenous variables have at the most three (3) incoming paths, a minimum sample of 30 is needed. Furthermore, we used the Cohen (1998) power analysis for multiple regression analysis to calculate power values for the model. An a priori power analysis given medium size effect and error probability of 0.05 results in an obtained power of 0.803 , which exceeds the suggested threshold of 0.8 given by Cohen (1998), and requiring a minimum sample size of 82 . The 115 responses used in this study are therefore sufficient for adequate statistical power to be obtained. 


\begin{tabular}{|c|c|c|c|}
\hline \multicolumn{4}{|c|}{ Table 1. Descriptive Statistics of firms } \\
\hline Number of Employees & Frequency & Percent & Cumulative Percent \\
\hline Less than 60 & 12 & 10.4 & 10.4 \\
\hline $60-99$ & 11 & 9.6 & 20.0 \\
\hline $100+$ & 91 & 79.1 & 99.1 \\
\hline Missing & 1 & 0.9 & 100.0 \\
\hline Total & 115 & 100.0 & \\
\hline Company's Industry & Frequency & Percent & Cumulative Percent \\
\hline Manufacturing & 9 & 7.8 & 7.8 \\
\hline Financial Services (banking \& investments) & 80 & 69.6 & 77.4 \\
\hline Oil and Gas & 1 & 0.9 & 78.3 \\
\hline Health & 2 & 1.7 & 80.0 \\
\hline Transportation & 2 & 1.7 & 81.7 \\
\hline Mining and Minerals & 10 & 8.7 & 90.4 \\
\hline Automobile and Heavy Equipment & 4 & 3.5 & 93.9 \\
\hline Other & 7 & 6.1 & 100.0 \\
\hline Total & 115 & 100.0 & \\
\hline Company's Annual Revenue (in Ghana Cedis) & Frequency & Percent & Cumulative Percent \\
\hline Less than 500,000 & 18 & 15.7 & 15.7 \\
\hline $500,000-1,000,000$ & 7 & 6.1 & 21.7 \\
\hline$>1,000,000$ & 90 & 78.3 & 100.0 \\
\hline Total & 115 & 100.0 & \\
\hline Ownership of Company & Frequency & Percent & Cumulative Percent \\
\hline Solely Ghanaian Owned & 75 & 65.2 & 65.2 \\
\hline Foreign Owned & 33 & 28.7 & 93.9 \\
\hline Joint Ventureship & 5 & 4.3 & 98.3 \\
\hline Other & 2 & 1.7 & 100.0 \\
\hline Total & 115 & 100.0 & \\
\hline Legal form of Entity & Frequency & Percent & Cumulative Percent \\
\hline Not Registered & 1 & 0.9 & 0.9 \\
\hline Limited Liability & 91 & 79.1 & 80.0 \\
\hline Partnership & 4 & 3.5 & 83.5 \\
\hline Public Limited Liability & 16 & 13.9 & 97.4 \\
\hline Other & 3 & 2.6 & 100.0 \\
\hline Total & 115 & 100.0 & \\
\hline
\end{tabular}

Measurement model analysis largely followed the treatment used by Karimi et al. (2007). First, the psychometric properties of the measurement model results were assessed by inspecting the individual item loadings, internal consistency, convergent validity, and discriminant validity. We first performed a confirmatory factor analysis (CFA) to test for the reliability of the research items used in the model. Poor factor loadings were observed for BPC2 and BPC3 and these items were removed from the analysis as recommended by Hair et al. (2010). All the remaining reflective indicators demonstrated acceptable factor loadings above the recommended threshold of 0.7 , suggesting acceptable reliability. For formative indicators, the item weights, which will usually have smaller absolute values than item loadings, were examined as recommended by Diamantopoulos and Winklhofer (2001). As seen in Appendix B, the weights for the formative construct, ERPEX, ranged from 0.44 to 0.82 and are statistically significant. 
Convergent validity is considered adequate when the average variance extracted (AVE) is 0.50 or more. AVE measures the amount that a latent variable component captures from its indicators as opposed to the amount due to measurement error. The results in Appendix B show that all constructs had acceptable AVE, indicating acceptable convergent validity. Composite reliability measures the ability of the indicators to explain the variance of their latent variable and is considered a better test of unidimensionality than Cronbach alpha because it considers the actual loading of the items (Chin, 1998). A rule of thumb benchmark of values of minimum 0.7 is used to assess acceptability of unidimensionality of a latent construct. The results in Appendix B show that all latent constructs passed this test as well.

Discriminant validity examines the extent to which a measure correlates with measures of constructs that are different from the construct the measure is intended to assess (Barclay et al. 1995). Thus, adequate discriminant validity will be achieved in a model when a construct shares more variance with its scale items than it shares with another construct within the model (Barclay et al., 1995). The factor loading for all the constructs, presented in Appendix $\mathrm{C}$, indicates good discriminant validity as the loading of each measurement item on its latent variable is larger than its loading on any other construct.

Table 2 shows the correlation among constructs. The ERPDS construct was more strongly correlated to BPO than ERPEX and ERPRAD. Although PLS is reasonably robust against multicollinearity and skewed responses (Cassel et al., 2000), we tested for acceptable multicollinearity and skewness. We did not observe a high level of association between the exogenous constructs. Further, an examination of the variance inflation factors (VIF) did not provide evidence of multicollinearity (Hair et al., 2010). Similarly, there was no evidence of prohibitive skewness or kurtosis detected.

\begin{tabular}{|l|c|c|c|c|}
\hline \multicolumn{5}{|c|}{ Table 2. Intercorrelation among latent constructs } \\
\hline \multirow{2}{*}{ Latent construct } & \multicolumn{3}{|c|}{ Interfactor correlations } \\
\cline { 2 - 5 } & $\mathbf{I}$ & II & III & IV \\
\hline I Extent of ERP Implementation (ERPEX) & $\mathbf{1}$ & & & \\
\hline II ERP radicalness (ERPRAD) & 0.0492 & $\mathbf{1}$ & & \\
\hline III ERP delivery system (ERPDS) & 0.2878 & 0.3055 & $\mathbf{1}$ & \\
\hline IV Business process outcomes (BPO) & 0.2229 & 0.2698 & 0.5720 & $\mathbf{1}$ \\
\hline
\end{tabular}

\subsection{Analysis of Second-Order formative constructs}

Second-order factor analyses followed the procedure of Diamantopoulos and Winklhofer (2001) in modelling the coefficients of the first-order factors to their second-order factors and performing a principal components factor analysis. According to Tanaka and Huba (1984), a high correlation of the first-order factors to second-order factors may be indicative of valid higher order relationship between them. From Figure 2, it is seen that the first-order factors correlate and are significantly different from zero, confirming their proposed second-order factor structure. Also, the absence of negative correlations among the constructs means that high values on one do not preclude a high value on another. Further, all intercorrelations among first-order constructs are below the recommended threshold of 0.90 (Bagozzi et al., 1991), indicating distinctiveness of the first-order factors and confirming discriminant validity of both formative constructs as depicted in Figure 2 below. 

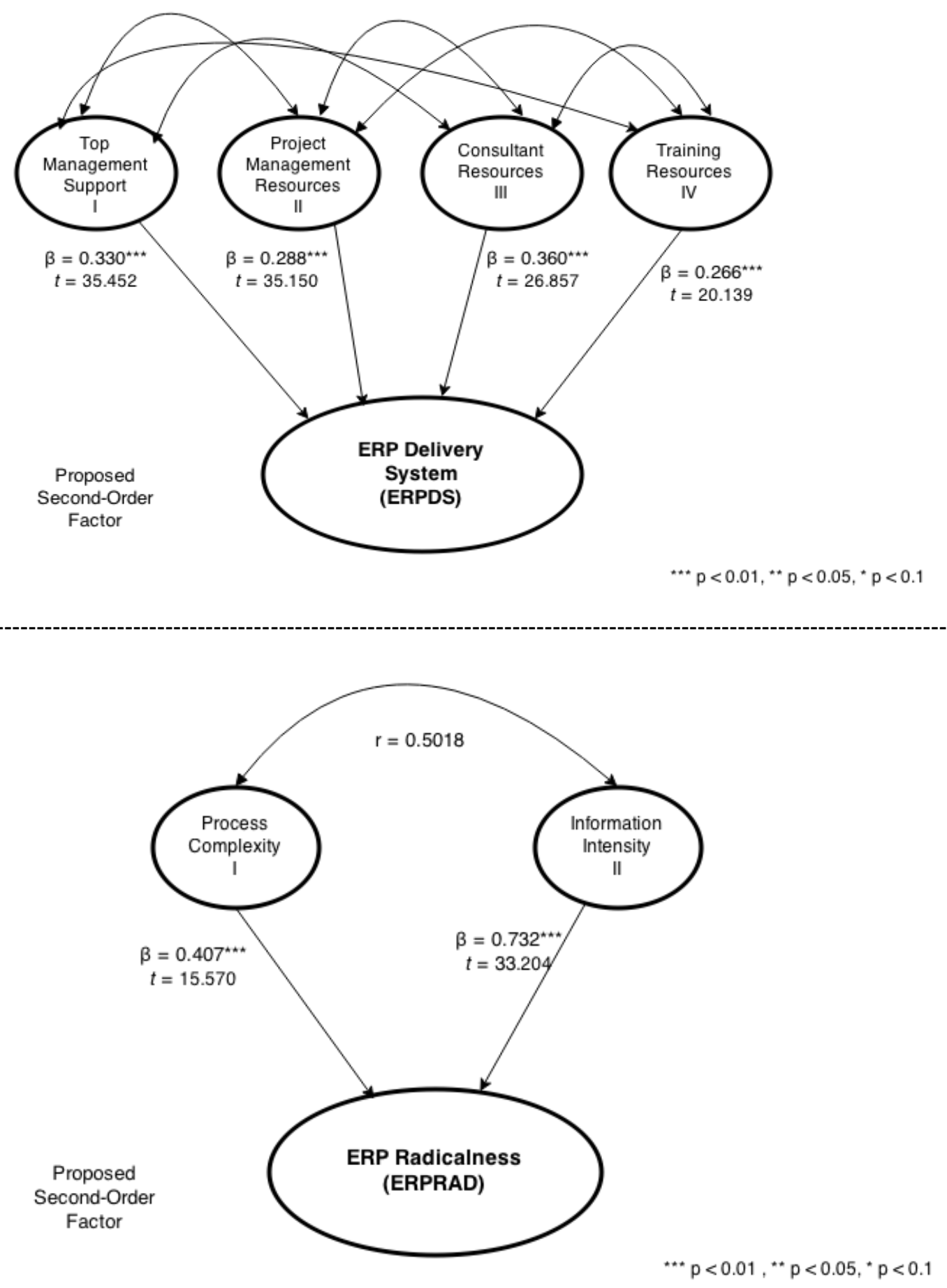

Figure 2. Second Order Construct Results

ERPDS $=\gamma 1(D S T M)+\gamma 2(D S P M)+\gamma 3(D S C O)+\gamma 4(D S T R)$

$E R P D S=0.330(D S T M)+0.288(D S P M)+0.360(D S C O)+0.266($ DSTR $)$

$$
\begin{gathered}
\text { ERPRAD }=y 1(B P I)+y 2(B P C) \\
\text { ERPRAD }=0.732(B P I I)+0.407(B P C)
\end{gathered}
$$


Content validity was assessed by inspecting whether the indicator variables (aggregate measure weighted by first-order coefficients) correlated highly with their direct measurement items. First-order indicators serve as proxies of their second-order constructs, and can be used to ascertain content validity when the aggregate first-order construct variables suitably represent the intended construct (Tanriverdi, 2006). The correlations $(r=0.52, p<0.001$ and $r=0.50, p<0.001)$ for both constructs are indicative of acceptable content validity.

\subsection{Testing the Structural Model}

Analysis and empirical validation of our hypotheses was done using PLS analysis. The parameter estimate of the hypothesized structural path should be statistically significant with the hypothesized direction of the effect. The path coefficients depict the strength of the relationships between the constructs. SmartPLS 2.0 performs bootstrapping analysis to assess the statistical significance of the loadings and of the path coefficients (Ringle et al., 2005). Bootstrapping analysis is a non-parametric approach for estimating the precision of the PLS estimates. The significance of the hypothesized relations in this study were calculated using SmartPLS bootstrap with $n=115$ and 500 iterations following the suggestions of Hair et al. (2010).

The hypotheses presented earlier in the paper are evaluated and examined based on the results obtained in the PLS analysis. There were mixed results for the research model. The results of the PLS analysis reveals that all but one of the standardized path coefficients exceed the suggested minimum standard significance of 0.20 (Chin and Newsted, 1999). The predictive power of the model is also good, with the model predicting a considerable level of variance in BPO $\left(R^{2}=0.40\right)$. However, only one of the hypothesized paths in the research model was statistically significant (see Table 3). The main effect of the study indicated a negative relationship between ERPEX and BPO with an effect size of -0.211 .

\begin{tabular}{|c|c|c|c|c|c|}
\hline \multicolumn{6}{|c|}{ Table 3. Results of Hypotheses test } \\
\hline \multirow[b]{2}{*}{$\mathbf{H}_{\mathbf{s}}$} & \multirow[b]{2}{*}{ Hypothesized paths } & \multicolumn{2}{|c|}{ Karimi et al. (2007) } & \multicolumn{2}{|c|}{ Our results } \\
\hline & & $\begin{array}{c}\text { Path } \\
\text { Coefficient } \\
\text { (Critical Ratio) }\end{array}$ & \begin{tabular}{|c|} 
Hypothesis \\
Support
\end{tabular} & \begin{tabular}{|c|} 
Path \\
Coefficient \\
(Critical Ratio) \\
\end{tabular} & \begin{tabular}{|c|} 
Hypothesis \\
Support
\end{tabular} \\
\hline $\mathrm{H}_{1}$ & $\begin{array}{l}\text { Extent of ERP Implementation (ERPEX) } \rightarrow \\
\text { business process outcome (BPO) }\end{array}$ & \begin{tabular}{c|}
0.313 \\
$(3.765)^{* *}$ \\
\end{tabular} & Supported & \begin{tabular}{|l|}
-0.211 \\
$(1.142)$ \\
\end{tabular} & $\begin{array}{c}\text { Not } \\
\text { supported }\end{array}$ \\
\hline $\mathrm{H}_{2}$ & $\begin{array}{l}\text { Extent of ERP Implementation (ERPEX) } \times \text { delivery } \\
\text { system (ERPDS) } \rightarrow \text { business process outcome } \\
(\text { BPO) }\end{array}$ & $\begin{array}{c}0.247 \\
(3.914)^{*}\end{array}$ & Supported & $\begin{array}{c}0.195 \\
\left(4.891^{\star \star}\right)\end{array}$ & Supported \\
\hline $\mathrm{H}_{3}$ & $\begin{array}{l}\text { Extent of ERP Implementation (ERPEX) } \times \text { ERP } \\
\text { radicalness (ERPRAD) } \rightarrow \text { business process } \\
\text { outcome (BPO) }\end{array}$ & $\begin{array}{c}0.251 \\
(3.681)^{* *}\end{array}$ & Supported & $\begin{array}{c}0.324 \\
(1.430)\end{array}$ & $\begin{array}{l}\text { Not } \\
\text { supported }\end{array}$ \\
\hline $\mathrm{H}_{4}$ & $\begin{array}{l}\text { ERP radicalness }(\text { ERPRAD) } \times \text { delivery system } \\
(\text { ERPDS }) \rightarrow \text { business process outcome }(\text { BPO) }\end{array}$ & $\begin{array}{c}0.147 \\
(2.330)^{* \star *}\end{array}$ & Supported & $\begin{array}{c}0.058 \\
(0.190)\end{array}$ & $\begin{array}{c}\text { Not } \\
\text { supported }\end{array}$ \\
\hline & ${ }^{*} p<0.001 ;{ }^{* *} p<0.01 ;{ }^{* * *} p<0.05$ & & & & \\
\hline
\end{tabular}

A post-hoc statistical power analysis revealed that this negative relationship was highly statistically significant. This would initially suggest that higher extent of ERP implementation is not positively associated with higher business process outcomes among Ghanaian firms. The negative effect of the relationship makes the findings even more interesting, since other studies have also observed that ERP implementations have not resulted in significant benefits to implementing organizations due to several challenges (Kim et al., 2005; Scot and Vessey, 2002; Sia and Soh, 2002).

\subsection{The Moderating Role of ERPDS and ERPRAD}

We then proceeded to measure the moderating effects, which can become the basis for determining contingency conditions regarding the results of the study. As shown in Table 3, ERPDS had a significant moderating effect $(\beta=0.195 ; t=4.891 ; p<0.01)$ on the relationship between ERPEX and BPO $\left(\mathrm{H}_{2}\right.$ 
supported). However, ERPRAD did not significantly positively moderate the relationship between ERPEX and BPO $(\beta=0.324 ; t=1.430)$, meaning $\mathrm{H}_{3}$ was not supported. Further, ERPDS did not significantly moderate the relationship between ERPRAD and BPO $(\beta=0.058 ; t=0.190)$, therefore $\mathrm{H}_{4}$ was likewise not supported. Post-hoc power analyses however confirmed that both of the unsupported moderating effects $\left(\mathrm{H}_{3}\right.$ and $\left.\mathrm{H}_{4}\right)$ were not statistically significant. These results are in sharp contrast to the results of Karimi et al. (2007) who observed positive significant moderating influences for all three moderating relationships $\left(\mathrm{H}_{2}, \mathrm{H}_{3}\right.$, and $\left.\mathrm{H}_{4}\right)$.

\begin{tabular}{|c|c|c|c|}
\hline \multicolumn{4}{|c|}{ Table 4. Alternative Results Model } \\
\hline Model & $\begin{array}{l}\text { Standardized } \\
\text { coefficient }\end{array}$ & t-statistic & $\mathbf{R}^{2}$ \\
\hline \multicolumn{4}{|l|}{ (1) $\mathrm{BPO}=f(\beta E R P E X)$} \\
\hline ERPEX & 0.223 & $5.647^{\star \star \star}$ & 0.050 \\
\hline \multicolumn{4}{|c|}{ (2) $\mathrm{BPO}=f\left(\beta E R P E X, \beta E R P E X^{\star}\right.$ ERPDS $)$} \\
\hline ERPEX & 0.050 & 1.613 & \multirow{2}{*}{0.384} \\
\hline ERPEX $\times$ ERPDS & 0.232 & $6.508^{* * *}$ & \\
\hline \multicolumn{4}{|c|}{ (3) $\mathrm{BPO}=f\left(\beta E R P E X, \beta E R P E X^{\star} E R P D S, \beta E R P D S^{*} E R P R A D\right)$} \\
\hline ERPEX & -0.251 & 1.473 & \multirow{3}{*}{0.400} \\
\hline ERPEX $x$ ERPDS & 0.194 & $4.653^{\star * *}$ & \\
\hline ERPRAD $\times$ ERPDS & 0.373 & $1.815^{\star}$ & \\
\hline \multicolumn{4}{|c|}{ (4) $\mathrm{BPO}=f\left(\beta E R P E X, \beta E R P E X^{\star} E R P D S, \beta E R P D S^{\star} E R P R A D, \beta E R P E X^{\star} E R P R A D\right)$} \\
\hline ERPEX & -0.211 & 1.092 & \multirow{4}{*}{0.400} \\
\hline ERPEX $\times$ ERPDS & 0.195 & $4.891^{* \star *}$ & \\
\hline ERPRAD $\times$ ERPDS & 0.058 & 0.190 & \\
\hline ERPEX x ERPRAD & 0.324 & 1.430 & \\
\hline \multicolumn{4}{|c|}{${ }^{*} p<0.1 ;{ }^{* *} p<0.05 ;{ }^{* * \star} p<0.01$} \\
\hline
\end{tabular}

Table 4 provides a summary of alternative model results that enable us further explore the relationship between ERPEX, BPO and the moderators. Model 1 comprises only the main effect of ERPEX impacting $\mathrm{BPO}$, and this was significant at $\mathrm{p}<0.01$ but explained only 5 percent of the variation in BPO. Model 2 builds on Model 1 by adding the interaction effect of ERPEX by ERPDS. This moderating influence of ERPDS on the relationship between ERPEX and BPO was highly significant, but had a strong impact on the primary effect of ERPEX on BPO, causing its strength to diminish from 0.223 to 0.050 . Variation of BPO explained however rises sharply from 5 percent to 38.4 percent. Model 3 further builds on Model 2 and shows the relationship of the main effect (ERPEX) and two of the interaction effects (ERPEX $\times$ ERPDS, ERPDS $\times$ ERPRAD) to BPO. The model explains about 40 percent of the variance in BPO and the moderating effects are significant. However, the main effect (ERPEX $\rightarrow$ BPO) is negative $(-0.251)$. The final Model 4 (the research model of this study) shows that ERPEX is negatively associated with BPO and the three moderators significantly delineate how the association between ERPEX and BPO changes according to the different levels of delivery system and radicalness. $R^{2}$ remains at $40 \%$ for Model 4 . Testing for the moderated relationships was performed by drawing conclusions from $\Delta R^{2}$ prompted by the moderators because "the use of the path coefficient of an interaction term will lead to spurious conclusions" (Carte and Russell, 2003, p. 484). By comparing the $\mathrm{R}^{2}$ for the interaction model with the $\mathrm{R}^{2}$ for the main effect model, we can assess the strength of the moderating effects. The difference in $\mathrm{R}^{2}$ can be used to estimate the effect size in order to ascertain whether the interaction effects had a small (0.02), medium (0.15), or large effect (0.35) on BPO (Cohen, 1998). Model 1 (containing only ERPEX) was compared to Model 4 (containing ERPEX and the three moderating effects), and as seen in Table 5, the inclusion of the interaction effects increases $R^{2}$ from 0.05 to 0.40 . The interactions had a large effect size $\left(f^{2}=0.4-0.050 / 1-0.050=0.37\right)$. Thus, the relationship between ERPEX and BPO is moderated to a large degree by ERP delivery system and radicalness. 


\section{Discussion and Conclusions}

This study was conducted in order to evaluate the impact of ERP implementations on the business process outcomes of firms in a developing country in the SSA region. The study was intended to conceptually replicate the study conducted by Karimi et al. (2007) who explored the same phenomenon in the US, a developed nation. This allows us to compare implementation results from the two vastly different environments within which these two studies have been conducted. Whereas Karimi et al. (2007) observed positive significant impact of ERPEX on BPO, our study revealed a negative relationship between the pair for the research model (Model 4) with 40 percent of the variation in BPO explained. This would initially suggest that greater extent of ERP implementation does not result in greater business process outcomes. Interestingly, ERPEX significantly impacts on BPO positively in the absence of these moderating variables, although only 5 percent of the variation in BPO would be explained.

When we further assessed the association of extent of ERP implementation, delivery systems, and radicalness with business process outcomes in the context of the SSA country, the findings suggest that the extent of ERP implementation in isolation is directly and significantly associated with higher business process outcomes. Also, ERP delivery system was confirmed to have significant positive moderating effect on the relationship between ERPEX and BPO in the research model. This suggests that the association between ERPEX and BPO can be made stronger or weaker with higher and lower levels of delivery system support respectively. However, the relationship between ERPEX and BPO was not significantly positively moderated by ERPRAD, i.e., a higher ERPRAD did not occasion greater BPO arising from ERPEX in the Ghanaian environment. Similarly, the interaction of ERP delivery system and radicalness does not significantly moderate the association of the extent of ERP implementation with business process outcomes in the Ghanaian environment.

The results suggest the constructs developed by Karimi et al. (2007) are relevant in the SSA context (indicated by the excellent measurement model results), but because the elements of the Ghanaian and by extension the SSA environment (Mbarika et al., 2005; McDade and Spring, 2005) was not accounted for in the model, the structural model results were poor. However, the combined effects of moderating factors indicated a large effect size impact on BPO. In the case of this study, we propose that the unique business environment of Ghanaian firms introduce some peculiarities into the ERP adoption and implementation process that has to be managed in order for high BPO to be obtained. Some of these important variables could include poor business ethics among Ghanaian businesses, culture of corruption (Transparency International, 2012), underdeveloped data culture (Hung and Chang, 2005), and weak organizational control (Cardinal, 2001; Sarin et al., 2003), which are not captured under any of the constructs identified in the research model that was tested. Further, firms in the banking and financial services industry, which dominated in our survey, are likely to be different from those in the manufacturing industry, which were used in the original study, in terms of how ERP systems are utilized in organizational processes.

Our results, far from refuting the results of the original study, rather suggests that the generalizability of the Karimi et al.'s (2007) study may be bounded by the origin and context of the original study, in this case manufacturing firms in the United States. Thus, there is a need to examine the contextual variables in new environments and industries to extend and enhance the generalizability of the theoretical model relating Extent of ERP implementation to BPO. Thus, we should be cautious when generalizing the results of the original and replicated models beyond the context for which the model has been validated.

\section{Implications}

While only one of the hypothesis presented was supported from the study with three not supported, there are still relevant implications. We provide both theoretical and practical implications.

\subsection{Implications for Research}

Our study contributes to IS research by answering the call for replication studies in the information systems field in the same way other social science disciplines such as marketing have done (Valacich and Dennis 2014). The results of the measurement model are valid and reliable, consistent with that of the original study, enhancing the external validity of the constructs proposed in the original model. However, only one of the four hypotheses tested in the structural model was confirmed in the current study although all four were confirmed in the original study. Although Karimi et al. (2007) study has been cited almost 200 
times on Google Scholar, none of those studies is a replication. Replication of such an important theoretical model can enhance theoretical understanding. We add to the call for more replication studies ranging from pure replication to extension and generalizations to enhance the external validity of important theoretical IS models. In particular, exact replication can enhance the internal validity of this theoretical model (Kettinger and Lee, 1999).

This study contributes to building a cumulative knowledge in Extent of ERP and Business Process Outcomes. Since the focus of replication in organization science is not to falsify or confirm prior work, the differences in results between the Karimi et al. (2007) work and the current study do not negate the importance of the original study. They suggest a need for more studies to better understand ERP benefits. Understanding the process by which ERP influence BPO in different contexts can actually enhance the original study. While differences in original and replicated study can hamper potential conclusion, it has been observed that imprecision replication enhances the external validity of the original finding (Tsang and Kwan, 1999). Hence we encourage future research to include more contextual variables to enhance the overall validity of the original model. For the SSA region in particular, there is a need to include contextual variables like corruption, data culture, and ethics, which when properly managed could cause ERP implementations to have positive results in SSA and other regions. Our study has also expanded understanding of ERP studies in the sub region that has been neglected in IS research (Huang and Palvia, 2001; Mbarika et al., 2005).

Still with respect to context, most of the current study's participants are in the financial industry which is different from the manufacturing firms used in the original study. Second, most of the firms were SMEs. There are many noted challenges when implementing ERP in SMEs. As can be observed, even organizations that were classified as large in the replicated study may be considered medium with the original study. Hence differences in industry and organization size might be additional variables that need further analysis in extending the original model to the SSA context.

\subsection{Implications for Practice}

This study conceptually replicated an ERP study originally conducted in a developed country (USA) in a developing SSA country (Ghana) and compared the implementation results of both studies. Results showed that implementation results varied significantly, probably occasioned by unique contextual conditions introduced by the Ghanaian business environment (Mbarika et al., 2005; McDade and Spring, 2005). This raises the need for SSA managers to be ready to adapt their ERP implementations to consider contextual conditions that may be specific to their environments as they roll-out ERP systems. Also further research is needed to properly explore the contextual variables that are likely to affect ERP implementations in order to achieve the best possible results from ERP implementations in SSA countries.

Also, because ERP delivery systems led to increasing variance in potential outcomes from ERP implementations in our study, the dimensions of ERPDS (top management support, project management resources, consultant resources, and training resources) should receive considerable attention and management so as to increase the level of BPO arising from ERP implementations. These items can serve as managerial drivers for greater ERP implementation results in SSA. Given the difficulties that have been associated with ERP implementations, securing proper delivery systems prior to ERP implementation is critical for SSA business managers.

\section{Limitations and Future Research Directions}

There are a few limitations to the study. The replication wholly relied on the responses of respondents for all the measures used in this study. The likelihood of respondent bias is present. Further, actual data collection was restricted to only firms in Ghana, although the study considers what effect environmental forces thought to prevail in SSA countries might have on the ERP implementation results in the region (Mbarika et al., 2005).

The study has brought out several interesting findings concerning ERP implementation results among Ghanaian firms. However, some questions are still left unanswered by the study. For instance, the specific causes for the negative impact of extent of ERP implementation on business process outcomes could not be immediately determined and deserve further exploration. Also, the specific contextual variables, moderating factors and/or mediating influences affecting ERP implementations in the region, and which would cause positive effects of ERPEX on BPO have to be ascertained to improve theory and to serve as implementation guidelines for Ghanaian and SSA firms (Mbarika et al., 2005; McDade and Spring, 2005). 


\section{References}

Abdelghaffar, H., \& Abdel Azim, R. H. (2010). Significant factors influencing ERP implementation in large organizations: Evidence from egypt. Paper presented at the European, Mediterranean \& Middle Eastern Conference on Information Systems 2010 April 12-13 2010, Abu Dhabi, UAE.

Alshawi, S., Themistocleous, M., \& Almadani, R. (2004). Integrating diverse ERP systems: A case study. The Journal of Enterprise Information Management, 17(6), 454-462.

Amoako-Gyampah, K., \& Acquaah, M. (2008). Manufacturing strategy, competitive strategy and firm performance: An empirical study in a developing economy environment. International Journal of Production Economics, 111(2), 575-592.

AMR. (2008). The steady stream of ERP investments. Retrieved November 27, 2012 from http://www.amrresearch.com

Avgerou, C. (2008). State of the art information systems in developing countries: A critical research review. Journal of Information Technology, 23, 133-146.

Bagozzi, R. P., Yi, Y., \& Phillips, L. W. (1991). Assessing construct validity in organizational research. Administrative Science Quarterly, 36(3), 421-458.

Barclay, D., Higgins, C., \& Thompson, R. (1995). The partial least squares (PLS) approach to causal modeling: Personal computer adoption and use as an illustration. Technology studies, 2, 285-309.

Berthon, P., Pitt, L., Ewing, M., \& Carr, C. L. (2002). Potential research space in MIS: A framework for envisioning and evaluating research replication, extension, and generation. Information Systems Research, 13(4), 416-427.

Cardinal, B. L. (2001). Technological innovation in the pharmaceutical industry: The use of organizational control in managing research and development. Organization Science, 12(1), $19-36$.

Carte, T. A., \& Russell, C. J. (2003). In pursuit of moderation: Nine common errors and their solutions. MIS Quarterly, 27(3), 479-501.

Cassel, C. M., Hackl, P., \& Westlund, A. H. (2000). On measurement of intangible assets: A study of robustness of partial least squares. Total Quality Management, 11(7), 897-907.

Chin, W. W. (1998). Commentary: Issues and opinion on structural equation modeling. MIS Quarterly, 22(1), vii-xvi.

Chin, W. W., \& Newsted, P. R. (1999). Structural equation modeling analysis with small samples using partial least squares. Statistical Strategies for Small Sample Research, 1(1), 307-341.

Chou, S., \& Chang, Y. (2008). The implementation factors that influence the ERP (enterprise resource planning) benefits. Decision Support Systems, 46, 149-157.

Cohen, J. (1998). Statistical power analysis for the behavioral sciences. NJ: Erlbaum: Hillsdale.

Davis, G., Ein-Dor, P., King, W. R., \& Torkzadeh, R. (2006). IT offshoring: History, prospects and challenges. Journal of the Association for Information Systems, 7(1), 32.

Dennis, A. R., \& Valacich, J. S. (2014). A Replication Manifesto. AlS Transactions on Replication Research, 1, 1-5.

Diamantopoulos, A., \& Winklhofer, H. M. (2001). Index construction with formative indicators: An alternative to scale development. Journal of Marketing Research, 38(2), 269-277.

Elbashir, M. Z., Collier, P. A., \& Davern, M. J. (2008). Measuring the effect of business intelligence systems: The relationship between business process and organizational performance. International Journal of Accounting Information Systems, 9(3), 135-153.

Gargeya, V., \& Brady, C. (2005). Success and failure factors of adopting SAP in ERP system implementation. Business Process Management Journal, 11(5), 501-516.

Hair, J. F., Black, W. C., Anderson, R. E., \& Tatham, R. L. (2010). Multivariate data analysis (Vol. 7). Upper Saddle River, NJ: Prentice Hall. 
Huang, S., Hung, Y., Chen, H., \& Ku, C. (2004). Transplanting the best practice for implementation of an ERP system: A structured inductive study of an international company. Journal of Computer Information Systems, 44(4), 101-166.

Huang, Z., \& Palvia, P. (2001). ERP implementation issues in advanced and developing countries. Business Process Management Journal, 7(3), 276 -- 284.

Hung, S.-Y., \& Chang, C.-M. (2005). User acceptance of WAP services: Test of competing theories. Computer Standards \& Interfaces, 27, 359-370.

Karimi, J., Somers, T. M., \& Bhattacherjee, A. (2007). The impact of ERP implementation on business process outcomes (BPO): A factor-based study. Journal of Management Information Systems, 24(1), 101-134.

Kettinger, W. J., \& Lee., C. C. (1999). Replication of measures in information systems research: The case of IS SERVQUAL. Decision Sciences, 30(3), 893-899.

Kim, Y., Lee, Z., \& Gosain, S. (2005). Impediments to successful ERP implementation process. Business Process Management Journal, 11(2), 158-170.

Mbarika, V. W. A., Okoli, C., Byrd, T. A., \& Datta, P. (2005). The neglected continent of IS research: A research agenda for Sub-Saharan Africa. Journal of the Association for Information Systems, 6(5), 130-170.

McDade, B. E., \& Spring, A. (2005). The 'new generation of African entrepreneurs': Networking to change the climate for business and private sector-led development. Entrepreneurship \& Regional Development: An International Journal, 17(1), 17-42.

Moss, T., \& Majerowicz, S. (2012). No longer poor: Ghana's new income status and implications of graduation from IDA. CGD Working Paper 300. Washington, D.C.

Oppong, M., Owiredu, A., \& Churchill, R. Q. (2014). Micro and small scale enterprises development in Ghana. European Journal of Accounting Auditing and Finance Research, 2(6), 84-97.

Otieno, J. (2005). A framework for ERP implementation in developing countries: Kenyan case study. Paper presented at the Information Resource Management Association (IRMA) International Conference, San Deigo, California USA.

Ragowsky, A., Stern, M., \& Adams, D. A. (2000). Relating benefits from using IS to an organization's operating characteristics: Interpreting results from two countries. Journal of Management Information Systems, 16(4), 175-194.

Ringle, C. M., Wende, S., \& Will, A. (2005). SmartPLS 2.0.M3 (beta). Hamburg: University of Hamburg.

Roztocki, N., \& Weistroffer, H. R. (2008). Information technology investments in emerging economies. Information Technology for Development, 14(1), 1-10.

Roztocki, N., \& Weistroffer, H. R. (2009). Information and Communications Technology in Developing, Emerging and Transition Economies: An Assessment of Research. Paper presented at the Americas Conference on Information Systems, San Francisco, California.

Roztocki, N., \& Weistroffer, H. R. (2011). Information technology success factors and models in developing and emerging economies. Information Technology for Development, 17(3), 163-167.

Rubin, D. B. (1976). Inference and missing data. Biometrika, 63(3), 581-592.

Sarin, Shikhar, \& McDermott, C. (2003). The effect of team leadership on the learning and performance of cross-functional product development teams. Decision Sciences, 34(4), 707-739.

Scot, J., \& Vessey, I. (2002). Managing risks in enterprise systems implementations. Communications of The ACM, 43(4), 74-81.

Scott, F., \& Shepherd, J. (2002). The steady stream of ERP investments. AMR Research.

Sia, S., \& Soh, C. (2002). Severity assessment of ERP-organization misalignment: Honin in on ontological structure and context specificity. Paper presented at the 33rd International Conference on Information Systems (ICIS). 
Soh, C., \& Sia, S. (2004). An institutional perspective on sources of ERP package-organization misalignments. Journal of Strategic Information Systems, 13(4), 375-397.

Tanaka, J. S., \& Huba, G. J. (1984). Confirmatory hierarchical factor analysis of psychological distress measures. Journal of Personality and Social Psychology, 46(3), 631-635.

Tanriverdi, H. (2006). Performance effects of information technology synergies in multibusiness firms. MIS Quarterly, 30(1), 57-77

Transparency International. (2012). Corruption Index. Retrieved November, 192014 from (http://www.transparency.org/country\#gha).

Tsang, E. W., \& Kwan, K.-M. (1999). Replication and theory development in organizational science: A critical realist perspective. Academy of Management Review, 24(4), 759-780.

Voordijk, H., Stegwee, R., \& Helmus, R. (2005). ERP and the changing role of IT in engineering consultancy firms. Business Process Management Journal, 11(4), 418-430.

Zhang, L., Lee, M., Zhang, Z., \& Cheung, C. (2002). A framework of enterprise resource planning systems implementation success in China. Paper presented at the Pacific Asia Conference on Information Systems (PACIS). 


\section{Appendix A: Overview of Measurement Items}

\begin{tabular}{|l|l|l|}
\hline \multicolumn{3}{|c|}{ Table A1. Summary of Constructs and Research Items } \\
\hline Construct (Acronym) & Type of Construct & Number of Items \\
\hline Extent of ERP Implementation (ERPEX) & Formative Second order & \\
\hline Functional Scope (ESC1) & Formative First order & 1 \\
\hline Organizational Scope (ESC2) & Formative First order & 1 \\
\hline Geographic Scope (ESC3) & Formative First order & 1 \\
\hline ERP Radicalness (ERPRAD) & Reflective Second order & \\
\hline Business Process Information Intensity (BPII) & Reflective First order & 4 \\
\hline Business Process Complexity (BPC) & Reflective First order & 4 \\
\hline ERP Delivery System (ERPDS) & Formative Second order & \\
\hline Top Management Support (DSTM) & Reflective First order & 3 \\
\hline Project Management Resources (DSPM) & Reflective First order & 3 \\
\hline Training Resources (DSTR) & Reflective First order & 3 \\
\hline Consultant Resources (DSTR) & Reflective First order & 3 \\
\hline Process Management Capability (PMC) & Reflective Second order & \\
\hline Process Efficiency (EFCO) & Reflective First order & 4 \\
\hline Process Effectiveness (EFTO) & Reflective First order & 6 \\
\hline Process Flexibility (FLXO) & Reflective First order & 4 \\
\hline
\end{tabular}




\section{Appendix B: Factor analysis results for Constructs}

\begin{tabular}{|c|c|c|c|c|}
\hline \multicolumn{5}{|c|}{ Table B1: Measurement Model Results for Constructs } \\
\hline Constructs & Item mean & $\begin{array}{l}\text { Item Standard } \\
\text { Deviation }\end{array}$ & Item Loadings & t-statistic \\
\hline \multicolumn{5}{|c|}{ Extent of ERP implementation (ERPEX) } \\
\hline Functional scope & 4.21 & 1.360 & $0.5443^{2}$ & $2.271^{* * *}$ \\
\hline Organizational scope & 2.89 & 0.589 & $0.4408^{2}$ & $1.163^{*}$ \\
\hline Geographic scope & 2.40 & 0.846 & $0.8228^{2}$ & $7.035^{* * *}$ \\
\hline \multicolumn{5}{|c|}{ ERP radicalness (ERPRAD) } \\
\hline \multicolumn{5}{|c|}{ Business process information intensity (BPII) } \\
\hline BPII1 & 6.50 & 0.831 & 0.783 & $41.888^{* * *}$ \\
\hline BPII2 & 6.23 & 0.946 & 0.772 & $35.051^{* * *}$ \\
\hline BPII3 & 6.31 & 0.912 & 0.755 & $23.579^{* * *}$ \\
\hline BPII4 & 6.40 & 0.867 & 0.714 & $26.572^{* * *}$ \\
\hline \multicolumn{5}{|c|}{ Composite Reliability $=0.842423 ; \mathrm{AVE}=0.572330$} \\
\hline \multicolumn{5}{|c|}{ Business process complexity (BPC) } \\
\hline BPC1 & 6.15 & 0.881 & 0.832 & $42.988^{* * *}$ \\
\hline BPC4 & 4.73 & 1.366 & 0.741 & $24.978^{* * *}$ \\
\hline \multicolumn{5}{|c|}{ Composite Reliability $=0.765362 ; \mathrm{AVE}=0.620833$} \\
\hline \multicolumn{5}{|c|}{ ERP delivery system (ERPDS) } \\
\hline \multicolumn{5}{|c|}{ Top management support (DSTM) } \\
\hline DSTM1 & 5.77 & 1.193 & 0.847 & $54.559^{* * *}$ \\
\hline DSTM2 & 5.81 & 1.228 & 0.884 & $46.736^{* * *}$ \\
\hline DSTM3 & 5.68 & 1.174 & 0.920 & $133.703^{* \star *}$ \\
\hline \multicolumn{5}{|c|}{ Composite Reliability $=0.914945 ;$ AVE $=0.782127$} \\
\hline \multicolumn{5}{|c|}{ Project management resources (DSPM) } \\
\hline DSPM1 & 5.36 & 1.133 & 0.795 & $34.445^{\star * \star}$ \\
\hline DSPM2 & 5.59 & 1.059 & 0.840 & $63.433^{* * *}$ \\
\hline DSPM3 & 5.27 & 1.037 & 0.765 & $36.161^{* * *}$ \\
\hline \multicolumn{5}{|c|}{ Composite Reliability $=0.842572 ; \mathrm{AVE}=0.641147$} \\
\hline \multicolumn{5}{|c|}{ Training resources (DSTR) } \\
\hline DSTR1 & 5.80 & 1.010 & 0.780 & $30.213^{* * *}$ \\
\hline DSTR2 & 5.76 & 1.005 & 0.877 & $58.361^{* * *}$ \\
\hline DSTR3 & 5.58 & 1.059 & 0.792 & $39.895^{* \star}$ \\
\hline \multicolumn{5}{|c|}{ Composite Reliability $=0.857798 ; \mathrm{AVE}=0.668479$} \\
\hline \multicolumn{5}{|c|}{ Consultant resources (DSCO) } \\
\hline DSCO1 & 5.58 & 1.199 & 0.864 & $71.774^{* * *}$ \\
\hline DSCO2 & 5.25 & 1.220 & 0.883 & $56.121^{* \star *}$ \\
\hline DSCO3 & 5.21 & 1.158 & 0.888 & $85.700^{* * *}$ \\
\hline
\end{tabular}


Table B1: Measurement Model Results for Constructs

\begin{tabular}{|c|c|c|c|c|}
\hline Constructs & Item mean & $\begin{array}{l}\text { Item Standard } \\
\text { Deviation }\end{array}$ & Item Loadings & t-statistic \\
\hline \multicolumn{5}{|c|}{ Business process outcomes (BPO) } \\
\hline \multicolumn{5}{|l|}{ Process efficiency (EFCO) } \\
\hline EFCO1 & 5.83 & 1.102 & 0.867 & $111.689^{* \star *}$ \\
\hline EFCO2 & 4.90 & 1.318 & 0.800 & $37.947^{* \star \star}$ \\
\hline EFCO3 & 5.54 & 1.300 & 0.838 & $53.658^{\star \star \star}$ \\
\hline \multicolumn{5}{|c|}{ Composite Reliability = 0.873793; AVE $=0.697921$} \\
\hline \multicolumn{5}{|c|}{ Process effectiveness (EFTO) } \\
\hline EFTO1 & 5.82 & 1.097 & 0.811 & $51.148^{\star \star \star}$ \\
\hline EFTO2 & 5.86 & 1.042 & 0.754 & $26.989^{\star \star *}$ \\
\hline EFTO3 & 5.57 & 1.148 & 0.738 & $24.178^{* * *}$ \\
\hline EFTO4 & 5.30 & 1.026 & 0.725 & $27.929^{\star \star \star}$ \\
\hline EFTO5 & 5.38 & 1.073 & 0.834 & $48.470^{* * *}$ \\
\hline EFTO6 & 5.63 & 1.111 & 0.886 & $88.511^{\star \star \star}$ \\
\hline \multicolumn{5}{|c|}{ Composite Reliability $=0.910281 ;$ AVE $=0.629617$} \\
\hline \multicolumn{5}{|l|}{ Process flexibility $\quad(F L X O)$} \\
\hline FLXO1 & 5.40 & 1.083 & 0.761 & $27.859^{\star * \star}$ \\
\hline FLXO2 & 5.25 & 1.130 & 0.778 & $27.339^{\star \star \star}$ \\
\hline FLXO3 & 5.62 & 1.022 & 0.832 & $47.266^{* \star *}$ \\
\hline FLXO4 & 5.44 & 1.156 & 0.834 & $51.192^{\star \star *}$ \\
\hline
\end{tabular}




\section{Appendix C: Factor loadings and Cross-loadings}

\begin{tabular}{|c|c|c|c|c|c|c|c|c|c|c|}
\hline \multicolumn{11}{|c|}{ Table C1. Item loadings and cross-loadings } \\
\hline & BPC & BPII & DSCO & DSPM & DSTM & DSTR & EFCO & EFTO & ERPEX & FLXO \\
\hline BPC1 & 0.7622 & 0.4835 & 0.1074 & 0.2037 & 0.3049 & 0.2603 & 0.1498 & 0.2370 & 0.2744 & 0.1475 \\
\hline BPC4 & 0.7452 & 0.3450 & 0.1769 & 0.1271 & 0.2123 & 0.1905 & 0.2373 & 0.2070 & 0.0532 & 0.1795 \\
\hline BPII1 & 0.3291 & 0.7827 & 0.0926 & 0.1665 & 0.2644 & 0.1053 & 0.1668 & 0.2015 & -0.0652 & 0.1081 \\
\hline BPII2 & 0.3866 & 0.7717 & 0.0963 & 0.2341 & 0.2623 & 0.0489 & 0.1426 & 0.2501 & 0.0177 & 0.1521 \\
\hline BPII3 & 0.4288 & 0.7556 & 0.0665 & 0.0719 & 0.2555 & 0.0992 & 0.1238 & 0.1504 & -0.0128 & 0.0892 \\
\hline BPII4 & 0.4307 & 0.7141 & 0.1104 & 0.1364 & 0.2441 & 0.2481 & 0.0190 & 0.1542 & -0.0128 & 0.1353 \\
\hline DSCO1 & 0.1539 & 0.0630 & 0.8641 & 0.5202 & 0.4349 & 0.6145 & 0.2782 & 0.3059 & 0.1758 & 0.2873 \\
\hline DSCO2 & 0.1341 & 0.0831 & 0.8833 & 0.4857 & 0.3324 & 0.5014 & 0.4014 & 0.4593 & 0.1742 & 0.3546 \\
\hline DSCO3 & 0.1888 & 0.1677 & 0.8881 & 0.5890 & 0.4953 & 0.5303 & 0.3396 & 0.3874 & 0.1991 & 0.3842 \\
\hline DSPM1 & 0.2013 & 0.2912 & 0.4832 & 0.7953 & 0.5892 & 0.2598 & 0.1732 & 0.3679 & 0.2174 & 0.3866 \\
\hline DSPM2 & 0.0956 & 0.1936 & 0.4772 & 0.8398 & 0.4856 & 0.4076 & 0.3193 & 0.3910 & 0.0845 & 0.4638 \\
\hline DSPM3 & 0.1170 & -0.0081 & 0.5000 & 0.7653 & 0.4083 & 0.3868 & 0.3153 & 0.4251 & 0.1796 & 0.4265 \\
\hline DSTM1 & 0.1758 & 0.1864 & 0.4451 & 0.5360 & 0.8469 & 0.2767 & 0.1687 & 0.3856 & 0.2679 & 0.3549 \\
\hline DSTM2 & 0.3624 & 0.3957 & 0.3844 & 0.5441 & 0.8843 & 0.3244 & 0.1929 & 0.3354 & 0.2078 & 0.3403 \\
\hline DSTM3 & 0.2460 & 0.3167 & 0.4508 & 0.5605 & 0.9203 & 0.3513 & 0.2445 & 0.4374 & 0.2533 & 0.4668 \\
\hline DSTR1 & 0.2842 & 0.2065 & 0.4417 & 0.3583 & 0.3394 & 0.7799 & 0.2840 & 0.4095 & 0.2168 & 0.3314 \\
\hline DSTR2 & 0.3063 & 0.1258 & 0.5238 & 0.3579 & 0.2043 & 0.8772 & 0.3667 & 0.3732 & 0.1452 & 0.3496 \\
\hline DSTR3 & 0.1680 & 0.0738 & 0.5635 & 0.3584 & 0.3361 & 0.7923 & 0.2182 & 0.2391 & 0.2354 & 0.3010 \\
\hline EFCO1 & 0.2163 & 0.1420 & 0.3852 & 0.4112 & 0.4012 & 0.3290 & 0.8674 & 0.7083 & 0.1385 & 0.6789 \\
\hline EFCO2 & 0.0938 & 0.0644 & 0.2483 & 0.1773 & -0.0099 & 0.2668 & 0.7995 & 0.4008 & 0.0228 & 0.3270 \\
\hline EFCO3 & 0.2717 & 0.1557 & 0.3055 & 0.2059 & 0.0950 & 0.2810 & 0.8380 & 0.5549 & -0.0312 & 0.4829 \\
\hline EFTO1 & 0.2061 & 0.0759 & 0.3064 & 0.3491 & 0.2784 & 0.3022 & 0.6035 & 0.8112 & 0.1884 & 0.6834 \\
\hline EFTO2 & 0.3753 & 0.2753 & 0.3299 & 0.3764 & 0.3611 & 0.3491 & 0.5964 & 0.7537 & 0.0842 & 0.5651 \\
\hline EFTO3 & 0.2335 & 0.3441 & 0.3408 & 0.4075 & 0.3405 & 0.3040 & 0.4960 & 0.7384 & 0.2585 & 0.6124 \\
\hline EFTO4 & 0.1204 & 0.1909 & 0.4270 & 0.3824 & 0.3627 & 0.3139 & 0.4127 & 0.7249 & 0.2011 & 0.5644 \\
\hline EFTO5 & 0.2149 & 0.1488 & 0.3098 & 0.3525 & 0.3749 & 0.3345 & 0.4994 & 0.8345 & 0.2828 & 0.6583 \\
\hline EFTO6 & 0.2742 & 0.1823 & 0.3721 & 0.4736 & 0.3747 & 0.3707 & 0.6427 & 0.8858 & 0.1972 & 0.7690 \\
\hline ESC1 & 0.2156 & 0.1183 & 0.0249 & 0.1582 & 0.1904 & 0.1113 & 0.0168 & 0.1552 & 0.5437 & 0.1104 \\
\hline ESC2 & 0.0102 & -0.0905 & -0.0528 & 0.0229 & 0.0584 & -0.0019 & 0.0314 & 0.0746 & 0.4409 & 0.1547 \\
\hline ESC3 & 0.0773 & -0.0749 & 0.2677 & 0.1531 & 0.2202 & 0.2466 & 0.0602 & 0.2100 & 0.8232 & 0.1799 \\
\hline FLX01 & 0.0946 & 0.1133 & 0.3387 & 0.4514 & 0.3162 & 0.2634 & 0.4477 & 0.6344 & 0.2306 & 0.7609 \\
\hline FLXO2 & 0.1750 & 0.1568 & 0.2692 & 0.4160 & 0.2671 & 0.2722 & 0.4233 & 0.6339 & 0.1450 & 0.7780 \\
\hline FLXO3 & 0.1467 & 0.1318 & 0.2991 & 0.4348 & 0.4065 & 0.2908 & 0.5418 & 0.6238 & 0.2029 & 0.8315 \\
\hline FLXO4 & 0.1847 & 0.1137 & 0.3405 & 0.4076 & 0.4112 & 0.4441 & 0.5711 & 0.7144 & 0.1562 & 0.8340 \\
\hline
\end{tabular}




\begin{abstract}
About the Authors
David Asamoah is a Senior Lecturer at the Department of Information Systems and Decision Sciences of the Kwame Nkrumah University of Science and Technology (KNUST) School of Business. He received his Bachelor's degree in Electrical and Electronic Engineering, Master's degree in Business Administration and Ph.D. in Logistics \& Supply Chain Management all from KNUST. His research interests include IT applications in supply chain management, enterprise systems and quality management. In addition to being an ad-hoc reviewer for many conference proceedings and journal publications including International Journal of Supply Chain Management and Supply Chain Management: International Journal, he has served as both Chair and Committee Member for some international conferences. His works have been published in many journals including Management Research Review (Emerald), International Journal for Services and Standards, and Journal of Medical Marketing.
\end{abstract}

Francis Kofi Andoh-Baidoo is Associate professor in the department of Information Systems at the University of Texas Rio Grande Valley, USA. He obtained his PhD in Information Systems from Virginia Commonwealth University, Richmond. His research areas include Business Analytics, Data Mining, Enterprise Systems and ICT use. He has published in journals such as Expert Systems with Applications, Database for Advances in Information Systems, Information Systems Frontiers, IEEE Security \& Privacy, and the Journal of Information Technology Theory and Application. He serves on the editorial board of several IS journals.

Benjamin Agyei-Owusu is a graduate assistant at Kwame Nkrumah University of Science and Technology (KNUST) School of Business with the Department of Information Systems and Decision Sciences. He received his Bachelor's degree in Business Administration from KNUST, specializing in Logistics and Supply Chain Management, and served as a teaching and research assistant with the Department of Information Systems and Decision Sciences. He is currently a post-graduate student in the same institution. His research interests span across information systems and quality management.

Copyright $(2015$ by the Association for Information Systems. Permission to make digital or hard copies of all or part of this work for personal or classroom use is granted without fee provided that copies are not made or distributed for profit or commercial advantage and that copies bear this notice and full citation on the first page. Copyright for components of this work owned by others than the Association for Information Systems must be honored. Abstracting with credit is permitted. To copy otherwise, to republish, to post on servers, or to redistribute to lists requires prior specific permission and/or fee. Request permission to publish from: AIS Administrative Office, P.O. Box 2712 Atlanta, GA, 30301-2712 Attn: Reprints or via email from ais@aisnet.org. 